\title{
Microwave-assisted Extraction of Ochratoxin A from Roasted Coffee Beans: An Alternative Analytical Approach
}

\author{
Giulia Graziani ${ }^{1}$, Antonello Santini ${ }^{1}$, Rosalia Ferracane ${ }^{1}$ \& Alberto Ritieni ${ }^{1}$ \\ ${ }^{1}$ Department of Food Science, University of Napoli “Federico II”, Parco Gussone, Portici (Napoli), Italy \\ Correspondence: Giulia Graziani, Dipartimento di Scienza degli Alimenti, Università di Napoli "Federico II", \\ Parco Gussone, Portici (Napoli) 80055, Italy. Tel: 39-081-253-9361. E-mail: giulia.graziani@unina.it
}

Received: November 5, 2011

Accepted: November 17, 2011 Online Published: July 2, 2012

doi:10.5539/jfr.v1n3p121

URL: http://dx.doi.org/10.5539/jfr.v1n3p121

\begin{abstract}
Microwave-assisted extraction (MAE) followed by high performance liquid chromatography (HPLC) with a fluorescent detector (DAD) was used and developed for the quantitative analysis of the mycotoxin ochratoxin A (OTA) in commercial roasted coffee beans. This alternative approach has been compared with the conventional extraction that uses hydrogen carbonate aqueous solution followed by OchraTest immunoaffinity analysis. The effect of two experimental tunable MAE parameters (temperature and pressure) on the extraction efficiency of OTA have been investigated using coffee samples fortified at different contamination levels. The optimum extraction conditions were obtained using a temperature of $50{ }^{\circ} \mathrm{C}$ and a $500 \mathrm{~W}$ microwave power. OTA quantity extracted using MAE was similar to that obtained by conventional extraction from samples fortified at 5 , 10, and $100 \mathrm{ng} \mathrm{g}^{-1}$ levels. At a $20 \mathrm{ng} \mathrm{g}^{-1}$ level, MAE was more effective than the conventional method. The MAE setting parameters have been optimized showing both extraction time and solvent consumption have been considerably reduced, retaining high OTA recovery values.
\end{abstract}

Keywords: microwave assisted extraction, mycotoxin, ochratoxin A, contamination, coffee

\section{Introduction}

Ochratoxin A (OTA) is a nephrotoxic and nephrocarcinogenic mycotoxin produced by several fungal species from Aspergillus genus and Penicillium verrucosum (IARC, 1993; Mantle \& Chow, 2000; Abarca et al., 2004). It is most commonly found in cereals and cereal products, although a wide range of commodities have been reported as containing the toxin (Pohland et al., 1992; Varga et al., 1996; Trucksess et al., 1997; Denli \& Perez, 2010). The natural occurrence of OTA in green coffee beans was first reported by Levi et al. (1974).

The presence of OTA in commercial roasted coffee beans was reported for the first time in five out of 68 samples at a level of 3.2-17.0 $\mathrm{g} \mathrm{kg}^{-1}$ (Tsubouchi et al., 1988). In the last 10 years there has been an increased interest in using techniques involving microwave-assisted extraction and pressurised solvent extraction in analytical laboratories. The development of microwave assisted extraction was first reported by Ganzler and co-workers (Ganzler et al., 1986; Ganzler \& Salgo, 1987).

The aim of this study was the comparison between conventional and alternative extraction of ochratoxin A from roasted coffee beans, and an optimization of microwave extraction parameters in order to establish the better conditions for OTA recovery. The alternative extraction was carried out using a microwave-assisted extraction (MAE) in closed vessels which is associated with several benefits. In particular, MAE is speedy, low cost, effective, simple, and consistent. Extractions performed with this innovative technique are completed in 10-20 minutes, require only a small solvent amount compared to conventional techniques, and are, in particular, suitable for the rapid extraction from a large number of samples.

Microwaves are non-ionizing electromagnetic waves of frequency between $300 \mathrm{MHz}$ to $300 \mathrm{GHz}$ and positioned between the X- ray and infrared rays in the electromagnetic spectrum (Letellier, 1999). The effect of microwave energy is strongly dependent on the dielectric susceptibility of both the solvent and solid plant matrix (Zuloaga, 1999). There are two types of commercially available MAE systems: closed extraction vessels and focused microwave ovens (Pastor, 1997; Luque-Garcia, 2004).

The MAE with closed vessels performs extraction under controlled pressure and temperature. The closed-vessel systems can reach higher temperatures than open vessel systems because the increased pressure inside the vessel 
raises the boiling point of the solvents used. The higher temperatures in turn decrease the time needed for the microwave treatment. Less solvent is required. Because no evaporation occurs, there is no need continually to add solvent to maintain the volume. Also, the risk of contamination is avoided as a result there is little or no risk of airborne contamination. A correct choice of solvent is fundamental for obtaining an optimal extraction process. Solvent choice for MAE is dictated by the solubility of the target analyte, by the interaction between solvent and plant matrix, and finally by the microwave absorbing properties of the solvent (Letellier, 1999).

In the literature several studies on MAE applications are reported. This technique is largely applied to pesticides analysis (Satpathy et al., 2011), but only a few studies are focused on bioactive metabolites, e.g. mycotoxins. In particular, MAE has been used for the extraction of polyphenols, caffeine, tanshinones, pyrimidine glycosides, gossypol, alkaloids, terpenes, essential oils, carotenoids, steroids, and taxanes. A recent paper of Liazid et al. (2007) reports that MAE could be a viable technique for OTA microwave-assisted extraction at temperatures up to $150{ }^{\circ} \mathrm{C}$, in a time frame up to $20 \mathrm{~min}$ without any sample degradation. There is however lack of information about the extraction conditions. This novel experimental research analyzes different extractive parameter settings, in order to obtain the best recovery of ochratoxin A. The described procedure allowed to optimize the MAE extraction method, allowing to assess its use with major advantages with respect to conventional methodologies that use hydrogen carbonate aqueous solution extraction. The proposed method is more efficient also compared to the results shown in a recent paper demonstrating that the efficiency of the bioactive compounds extraction obtained with the microwave assisted process is, in general, about four times higher with respect to the efficiency of the ultra sounds assisted extraction process (Gallo et al., 2010).

\section{Materials and Methods}

\subsection{Chemicals and Reagents}

OTA standard was purchased from Sigma-Aldrich (St. Louis, MO, USA). Methanol, acetic acid, and sodium hydrogen carbonate, were obtained from Merck (Darmstadt, Germany) and were of analytical grade. Acetonitrile and water were of HPLC grade (Lichrosolv, Merck). Distilled water was obtained using a Millipore Milli-Q instrument (Milford, MA). Phosphate-buffered saline (PBS) solution was made as $0.138 \mathrm{M} \mathrm{NaCl}$ and $2.7 \mathrm{mM}$ $\mathrm{KCl}$ in $0.01 \mathrm{M}$ phosphate buffer, $\mathrm{pH}$ 7.4. The roasted coffee was provided by the manufacturer ("Caffee Moak", Modica, RG, Italy). Coffee beans were cultivated in Cameroon.

\subsection{Microwave-assisted Extraction (MAE) of OTA}

For the microwave assisted extraction, an ETHOS 1 microwave-oven (Milestone, Shelton, CT, USA) equipped with 10 TFM Teflon closed vessels and an ATC-400FO Automatic Fiber Optic temperature control system was used. Before the analysis coffee samples were spiked with OTA standard at four different levels: 5, 10, 20 and $100 \mathrm{ng} \mathrm{g}^{-1}$. Three vessels, for each spiked sample, were simultaneously extracted (2.5 g of roasted coffee +50 $\mathrm{mL}$ of water with $1 \%$ of sodium hydrogen carbonate) using different microwave power. Extractions were first carried out at different temperatures keeping the power at the constant value of $500 \mathrm{~W}$ (selected as the better value to optimize the OTA recovery). Subsequently, three different extractions were carried out at 300, 500 and $700 \mathrm{~W}$ setting, at a temperature of $50^{\circ} \mathrm{C}$ (the better value for OTA recovery).

In particular, we investigated the effect of the temperature on the extraction effectiveness of OTA from roasted coffee. The extraction was carried out following the program as detailed in Table 1.

Table 1. Conditions (time, power, and temperature) used for microwave extraction

\begin{tabular}{llll}
\hline Step & Time $(\mathrm{min})$ & Temperature $\left({ }^{\circ} \mathrm{C}\right)$ & Power $($ Watt $)$ \\
\hline 1 & 5 & $40-50-100-120$ & $300-500-700$ \\
2 & 10 & $40-50-100-120$ & $300-500-700$ \\
ventilation & 5 & & \\
\hline
\end{tabular}

All the extractions were conducted using magnetic stirring at $50 \%$ of nominal power. After the microwave irradiation, the vessels were cooled in open air, and after cooling the mixtures were filtered. The filtrates were used for the OTA clean up and used for the HPLC analysis.

\subsection{Conventional Extraction of OTA}

Five grams of coffee sample were weighed in an Erlenmeyer flask, and then OTA was extracted with $100 \mathrm{~mL}$ of 
a $1 \%$ aqueous solution of sodium hydrogen carbonate with magnetic stirring for $30 \mathrm{~min}$.

The extract was filtered through Whatman n. 3 filter paper. An aliquot of $4 \mathrm{~mL}$ filtrate was diluted to $100 \mathrm{~mL}$ with phosphate-buffered saline (PBS), applied to an OchraTest immunoaffinity column and then quantified by reversed-phase HPLC with fluorescence detection.

\subsection{Clean up of OTA}

After extraction samples were filtered and centrifuged at $4000 \mathrm{rpm}$ for $10 \mathrm{~min}$. Subsequently $4 \mathrm{~mL}$ of supernatant were diluted to $100 \mathrm{~mL}$ with phosphate-buffered saline (PBS) and applied to an OchraTest immunoaffinity column containing a monoclonal antibody specific for OTA (Vicam Inc., Watertown, MA). After washing with $10 \mathrm{~mL}$ of distilled water, the OTA was eluted with $4 \mathrm{~mL}$ of methanol and quantified by reversed-phase HPLC with fluorescence detection.

\subsection{HPLC Analysis of OTA}

Detection and quantification were performed by HPLC using a Shimadzu chromatograph equipped with a RF-10AXL fluorescent detector, 2 binary pumps model LC-10AD $\mathrm{VP}_{\mathrm{V}}$, a system controller model SCL-10A a BioRad C18 HL 90-5 S 150 x 4.6 mm column. A binary chromatographic time program (\%B: 0.0 min, $50 ; 15.0$ min, $100 ; 18.0 \mathrm{~min}, 50 ; 23.0 \mathrm{~min}, 50 ; 23.0 \mathrm{~min}$, stop) was used with the follows mobile phase composed of acetonitrile/acetic acid (49:1) (B) and water/acetic acid (49:1) (A) pumped at a constant flow rate of $1 \mathrm{~mL} / \mathrm{min}$. The fluorimetric excitation and emission wavelengths were set at 333 and $460 \mathrm{~nm}$, respectively. OTA was quantified by comparison with external standard. The detection limit was $10 \mathrm{ng} \mathrm{kg}^{-1}$, and the quantification limit was $100 \mathrm{ng} \mathrm{kg}^{-1}$ with a rate noise to signal of 3 .

\section{Results and Discussion}

There has recently been widespread interest in the application of microwave heating to the analysis of active compounds from plants and herbs, but few applications have been described regarding mycotoxin extraction using MAE.

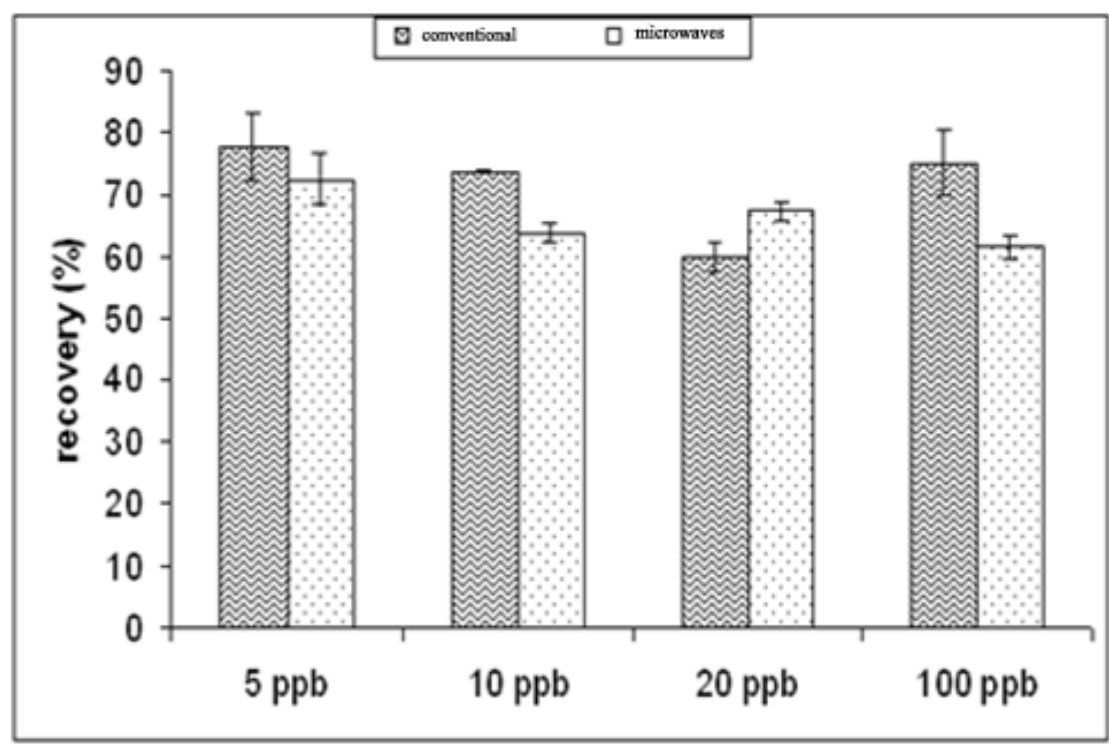

Figure 1. Ochratoxin A recovery of coffee samples spiked with different amounts of OTA. The extraction was carried out at $50^{\circ} \mathrm{C}$ and using a microwave power of $500 \mathrm{~W} . n=6$

To evaluate the extractive efficiency of OTA recovery using MAE, roasted coffee samples spiked at four different levels with OTA standard $\left(5,10,20\right.$ and $\left.100 \mathrm{ng} \mathrm{g}^{-1}\right)$ have been used, and this allowed us also to estimate the effect of parameters such as irradiation power and temperature on OTA extractive yields. Initially, coffee samples have been extracted using a microwave power of $500 \mathrm{~W}$ and setting the temperature at $50^{\circ} \mathrm{C}$ on the basis of previous experiments carried out by Liazid et al. (2007). In particular, microwave extraction was performed dissolving $2.5 \mathrm{~g}$ of roasted coffee into $50 \mathrm{~mL}$ of solvent (water with $1 \%$ of sodium bicarbonate) spiking the coffee powder with different amounts of ochratoxin A in order to asses the recovery at different 
spiked levels in comparison with conventional extraction. As shown in Figure 1, the average recovery for conventional extractions was of $71.5 \%$ while the average recovery of microwave extractions was of $66.2 \%$. In particular, MAE was competitive for coffee samples spiked with OTA at $20 \mathrm{ng} \mathrm{g}^{-1}$, In this case, in fact we observed a recovery of $60 \%$ for conventional extraction while MAE allowed to reach a significant higher recovery of $67 \%$. In literature (Sibanda et al., 2002; Lobeau et al., $2002 \& 2005$ ) was reported that in naturally contaminated roasted coffees the OTA concentration is variable in a range between 0.5 and $6 \mathrm{~g} \mathrm{~kg}^{-1}$. Our data show that also the samples spiked at level of $5 \mathrm{ng} \mathrm{g}^{-1}$ are extracted effectively using MAE with an average recovery of $72.4 \%$ in comparison with conventional extraction which allows to obtain an average recovery of $77.6 \%$. According to obtained data, it is possible to propose microwave assisted extraction as an efficient method for the extraction of OTA from roasted coffees that can to be considered an alternative approach for fast extraction of OTA.

In order to evaluate the performance of different extraction conditions on OTA recovery we have carried out different extractions setting temperatures of $40-50-100$ and $120^{\circ} \mathrm{C}$ and irradiation power of $300-500$ and $700 \mathrm{~W}$ as described in materials and methods. In Figure 2 is reported HPLC chromatogram of a coffee sample spiked with ochratoxin at level of $10 \mathrm{ng} \mathrm{g}^{-1}$.

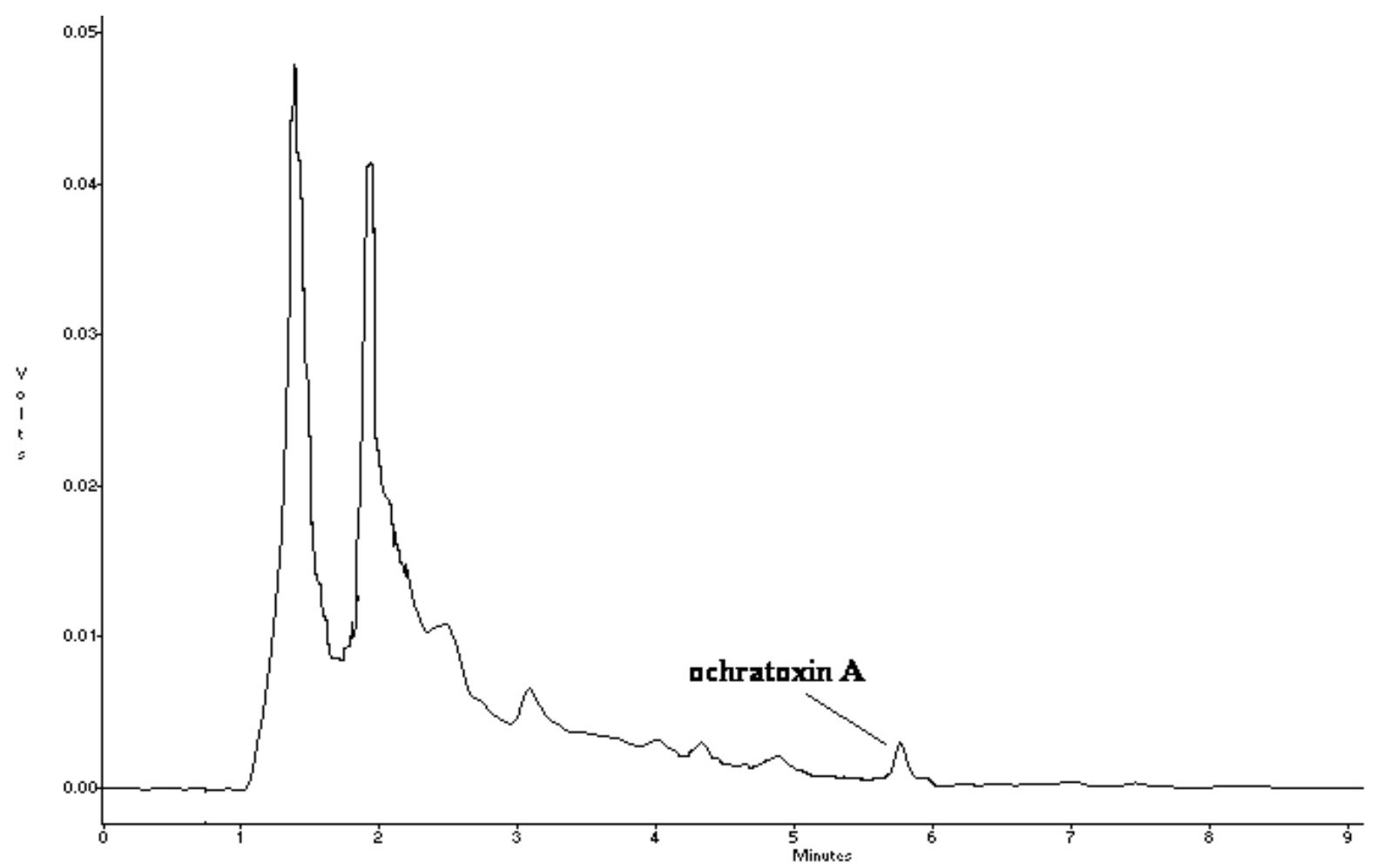

Figure 2. HPLC chromatogram of a coffee sample spiked with OTA at level of $10 \mathrm{ng} \mathrm{g}^{-1}$

\subsection{Temperature Effect}

The temperature monitoring of the sample inside the vessel was realised using an optic fibre probe hooked up to the control system. In order to evaluate the temperature effect on the extraction effectiveness, MAE extractions were performed at three different temperatures $\left(40,50,100\right.$ and $\left.120^{\circ} \mathrm{C}\right)$ and the power was kept at a constant value of $500 \mathrm{~W}$ for all the experiments. As can be observed in Figure 3, only the temperature of $40^{\circ} \mathrm{C}$ was the worst while all the others temperatures are able to extract OTA in the same way. In particular, at 50, 100 and $120^{\circ} \mathrm{C}$ samples spiked at $5 \mathrm{ng} \mathrm{g}^{-1}$ show the highest recovery (an average of $78 \%$ ), while all the others reached an average values of $68 \%$. All the extractions performed at $40^{\circ} \mathrm{C}$ are characterized by low recovery levels $(60 \%)$, therefore our results suggest that the optimal temperature for OTA extraction was $50^{\circ} \mathrm{C}$ in which it is possible to reach a extractive effectiveness comparable with conventional methodologies. 


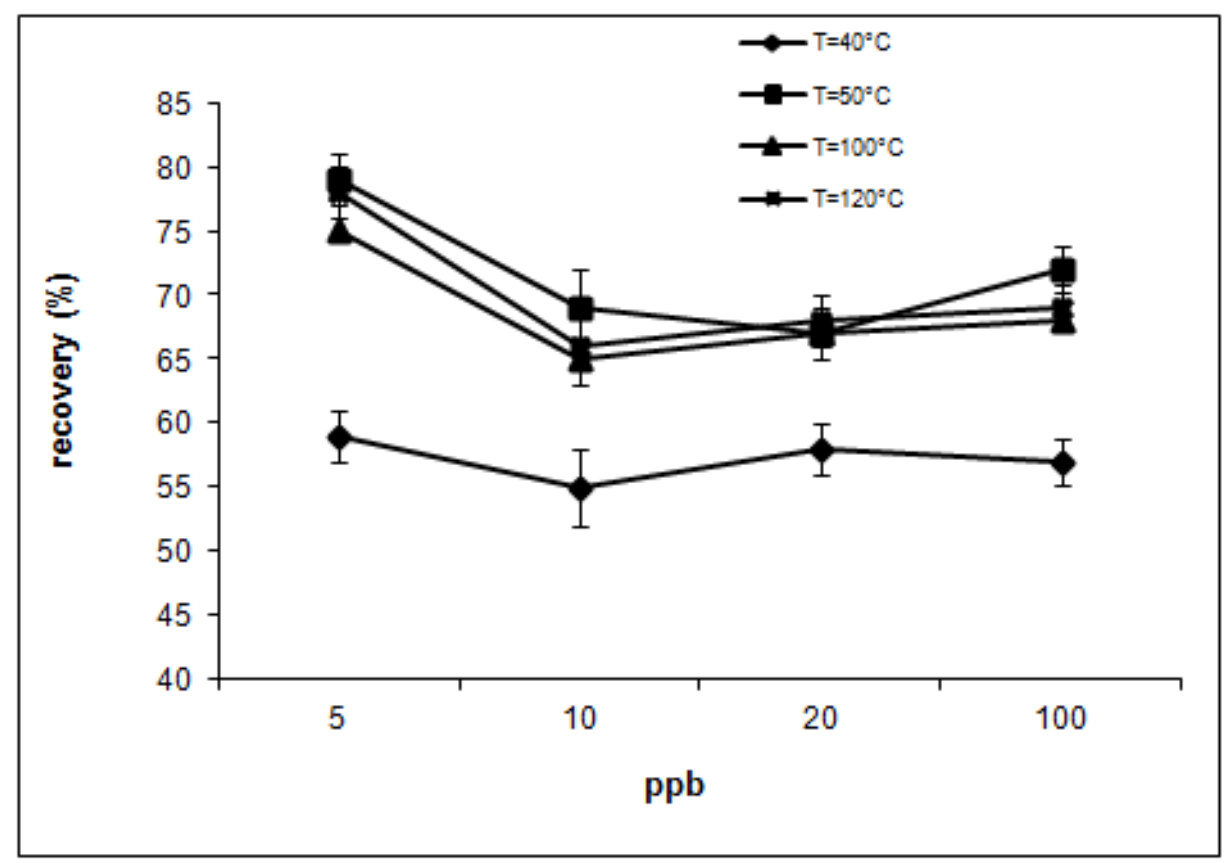

Figure 3. Effect of the temperature on the microwave extraction. Concentration is expressed as $\mathrm{g} \mathrm{kg}^{-1}\left(\mathrm{ng} \mathrm{g}^{-1}\right)$. $n=6$

In literature was reported that the temperature is a very important factor in ensuring efficient extraction because it increases the diffusivity of the solvent into the internal parts of the sample at high temperatures. At the same time, it also enhances desorption of the components from the active sites of the matrix. Llompart et al. 1997 reported that the better recoveries for phenols were obtained in closed vessels at elevated temperatures $\left(130^{\circ} \mathrm{C}\right)$ even though, in some cases, e.g. benzidine and organochlorinates pesticides, an increase in the temperature may be prejudicial to the extraction, due to the degradation of the components of interest. Pylypiw et al. (1997) suggested that the optimum temperature could be dependent on the matrix to be extracted. In fact, a temperature of $100^{\circ} \mathrm{C}$ was suitable for lettuces, while $120^{\circ} \mathrm{C}$ was the optimum temperature for tomatoes. In our case, increasing temperature was not critical for OTA recovery, reported to be unaffected by any temperature increase up to $150^{\circ} \mathrm{C}$ without degradation.

\subsection{Power Effect}

Coffee samples were extracted at three different microwave power $(300,500$ and $700 \mathrm{~W})$ and the temperature was kept at a constant value of $50{ }^{\circ} \mathrm{C}$ for all the experiments. The extraction procedure has been previously reported in materials and methods and the aim was to evaluate any possible effect of the microwave power irradiation on the OTA recovery. After a ventilation period of $5 \mathrm{~min}$ in which the samples were cooled down, the vessels were unsealed and each sample transferred to the filtering device and then to OTA clean up before the HPLC analysis.

In closed vessel systems, the chosen power setting depends on the number of samples to be extracted during one extraction run, as up to 12 vessels can be treated in a single run. The power must be chosen correctly to avoid excessive temperatures, which could lead to solute degradation and overpressure inside the vessels.

Figure 4 shows the irradiation power effect on the microwave extraction. It can be observed that the power value of 500W represents the optimal value of microwave power to obtain the better OTA extraction. Mao et al. (2007) reported that any compounds such as salidroside and tyrosol in Rhodiola L. were extracted effectively at $400 \mathrm{~W}$ while the extraction performed at 200 and $700 \mathrm{~W}$ allowed to reach lower extractive performances. 


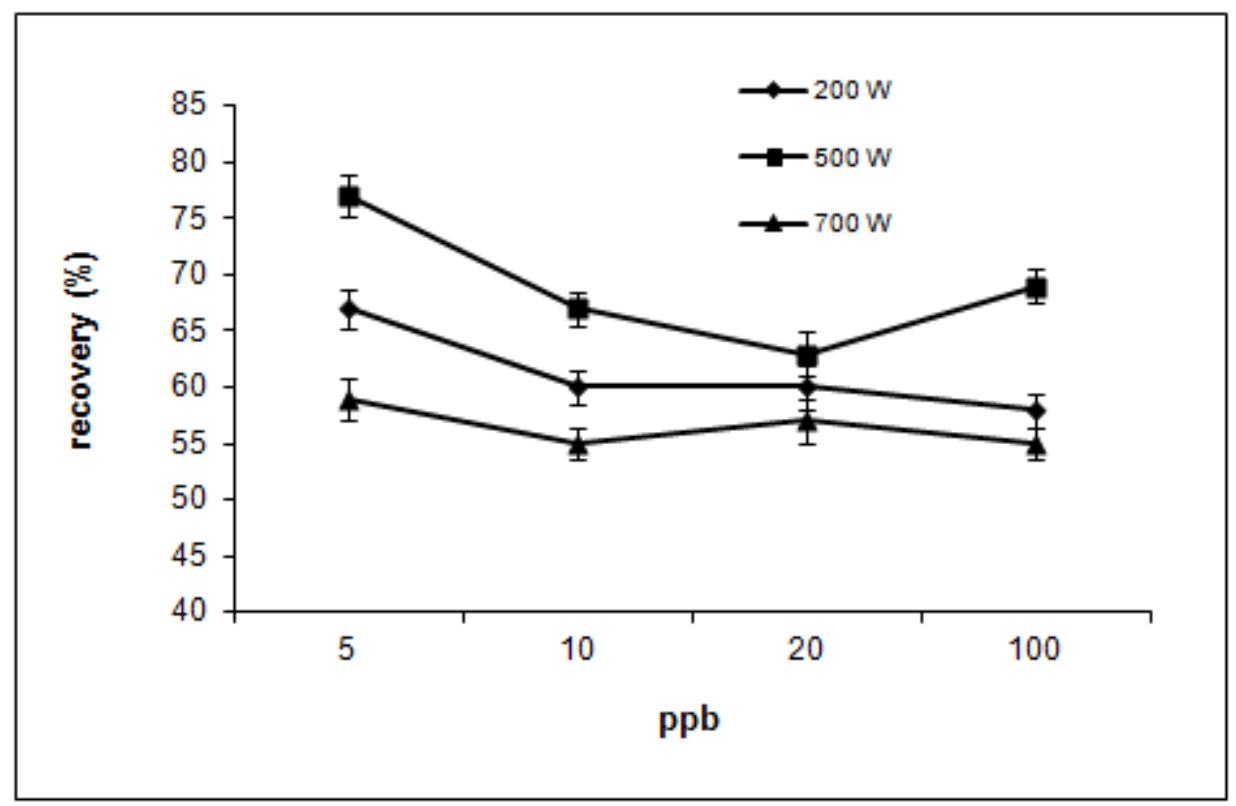

Figure 4. Irradiation power effect on microwave extraction. Concentration is expressed as $\mathrm{ppb}: \mathrm{g} \mathrm{kg}^{-1}\left(\mathrm{ng} \mathrm{g}^{-1}\right)$.

$$
n=6
$$

\section{Conclusions}

In this study the effect of microwave extraction parameters (irradiation power and temperature) on OTA recovery in roasted coffees spiked at different levels of OTA was determined in order to propose a simple, rapid and efficient method of analysis for the OTA determination in roasted coffee by HPLC.

The comparison with conventional extraction of OTA allows to speculate that MAE can be considered an alternative and innovative approach for OTA extraction from roasted coffee. This approach allowed to achieve quantitative recovery in $20 \mathrm{~min}$. Our data could be interesting especially for the coffee-processing industry: using this extraction technique it is possible to reduce the extraction time, the solvent use, and to obtain competitive extraction yields. Results of this study provide sound information for food industries always working on the task to meet the growing demand of consumers for healthier food products.

\section{Dedication}

This paper is dedicated to the memory of Dr. Maria Malanga.

\section{References}

Abarca, M., Bragulat, M. R., Castella, G., \& Cabanes, F. J. (2004). Ochratoxin A Production by Strains of Aspergillus niger var. niger. Applied and Environmental Microbiology, 60, 2650-2652.

Denli, M., \& Perez, J. F. (2010). Ochratoxins in feed, a risk for animal and human health: control strategies. Toxins, 2, 1065-1077. http://dx.doi.org/10.3390/toxins2051065

Gallo, M., Ferracane, R., Graziani, G., Ritieni, A., \& Fogliano, V. (2010). Microwave Assisted Extraction of Phenolic Compounds from Four Different Spices. Molecules, 15(9), 6365-6374. $\mathrm{http} / / / \mathrm{dx}$.doi.org/10.3390/molecules15096365

Ganzler, K., \& Salgò, A. (1987). Microwave extraction: a new method superseding traditional Soxhlet extraction.

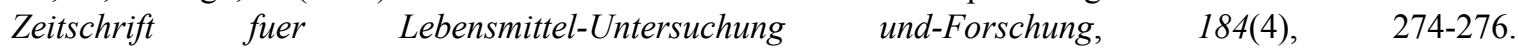
http://dx.doi.org/10.1007/BF01027662

Ganzler, K., Salgò, A., \& Valkò, K. (1986). Microwave extraction. A novel sample preparation method for chromatography. J. Chromatography, 371, 299-306. http://dx.doi.org/10.1016/S0021-9673(01)94714-4

IARC, \& Ochratoxin A. (1993). In: IARC Monographs on the Evaluation of Carcinogenic Risks to Humans: some naturally occurring substances; food items and constituents; heterocyclic aromatic amines and mycotoxins. International Agency for Research on Cancer, 56, 26-32.

Letellier, M., \& Budzinski, H. (1999). Microwave assisted extraction of organic compounds. Analusis, 27, 
259-271. http://dx.doi.org/10.1051/analusis:1999116

Letellier, M., Budzinski, H., Charrier, L., Capes, S., \& Dorthe, A. M. (1999). Optimization by factorial design of focused microwave assisted extraction of polycyclic aromatic hydrocarbons from marine sediment. J. Anal. Chemistry, 364, 228-237.

Levi, C. P., Trenk, H. L., \& Mohr, H. K. (1974). Study of the Occurrence of Ochratoxin A in Green Coffee Beans. J. Assoc. Off. Anal. Chemistry, 57, 866-870.

Liazid, A., Palma, M., Brigui, J., \& Barroso, C. G. (2007). Investigation on Ochratoxin A stability using different extraction techniques. Talanta, 71, 976-980. http://dx.doi.org/10.1016/j.talanta.2006.05.028

Llompart, M. P., Lorenzo, R. A., Cela, R., Jocelyn Parè, J. R., Bèlanger, J. M. R., \& Ken, L. (1997). Phenol and methy lphenol isomers determination in soils by in-situ microwave-assisted extraction and derivatisation. Journal of Chromatography A, 757, 153-164. http://dx.doi.org/10.1016/S0021-9673(96)00662-0

Lobeau, M., De Saeger, S., Sibanda, L., Barna-Vetrò, I., \& Van Peteghem, C. (2005). Development of a new clean-up tandem assay column for the detection of ochratoxin A in roasted coffee. Analytica Chimica Acta, 538, 57-61. http://dx.doi.org/10.1016/j.aca.2005.02.010

Lobeau, M., De Saeger, S., Sibanda, L., Barna-Vetro', I., \& Van Peteghem, C. (2002). Development of a Solid-Phase Cleanup and Portable Rapid Flow-Through Enzyme Immunoassay for the Detection of Ochratoxin A in Roasted Coffee. J. Agric. Food Chem., 50, 6964-6967. http://dx.doi.org/10.1021/jf020553o

Luque-Garcìa, J. L., \& Luque de Castro, M. D. (2004). Focused microwave-assisted Soxhlet extraction: devices and applications. Talanta, 64, 571-577. http://dx.doi.org/10.1016/j.talanta.2004.03.054

Mantle, P. G., \& Chow, A. M. (2000). Ochratoxin formation in Aspergillus ochraceus with particular reference to spoilage of coffee. International Journal of Food Microbiology, 56, 105-109. http://dx.doi.org/10.1016/S0168-1605(00)00278-6

Mao, Y., Li, Y., \& Yao, N. (2007). Simultaneous determination of salidroside and tyrosol in extracts of Rhodiola L. by microwave assisted extraction and high-performance liquid chromatography. Journal of Pharmaceutical and Biomedical Analysis, 45(3), 510-515. http://dx.doi.org/10.1016/j.jpba.2007.05.031

Pastor, A., Vàzquez Ciscar, R. M., \& de la Guardia, M. (1997) . Efficiency of the microwave-assisted extraction of hydrocarbons and pesticides from sediments. Analytica Chimica Acta, 344, 241-249. http://dx.doi.org/10.1016/S0003-2670(97)00012-3

Pohland, A. E., Nesheim, S., \& Friedman, L. (1992). Ochratoxin A: A review. Pure and Applied Chemistry, 64, 1029-1046. http://dx.doi.org/10.1351/pac199264071029

Pylypiw, H. M. Jr., Arsenault, T. L., Thetford, C. M., \& Mattina, M. J. I. (1997). Suitability of Microwave-Assisted Extraction for Multiresidue Pesticide Analysis of Produce. Journal of Agricultural and Food Chemistry, 45(9), 3522-3528. http://dx.doi.org/10.1021/jf970227m

Satpathy, G., Tyagi, Y. K., \& Gupta, R. K. (2011). A novel optimised and validated method for analysis of multi-residues of pesticides in fruits and vegetables by microwave-assisted extraction (MAE)-dispersive solid-phase extraction (d-SPE)-retention time locked (RTL)-gas chromatography-mass spectrometry with Deconvolution reporting software (DRS). Food Chemistry, 127(3), 1300-1308. http://dx.doi.org/10.1016/j.foodchem.2011.01.087

Trucksess, M. W., Giler, J., Yung, K., White, K. D., \& Page, S. W. (1999). Determination and survey of ochratoxin A in wheat, barley and coffee -1997. Journal of the AOAC International, 82, 85-89.

Tsubouchi, H., Terada, H., Yamamoto, K., Hisada, K., \& Sakabe, Y. (1988). Ochratoxin A found in commercial roast coffee. Journal of Agricultural and Food Chemistry, 36, 540-542. http://dx.doi.org/10.1021/jf00081a033

Varga, J., Kevei, E., Rinzu, E., Teren, J., \& Kozakiewicz, Z. (1996). Ochratoxin production by Aspergillus species. Applied and Environmental Microbiology, 62, 445-449.

Zuloaga, O., Etxebarria, N., Fernandez, L. A., \& Madariaga, J. M. (1999). Optimization and comparison of microwave assisted extraction and Soxhlet extraction for the determination of polychlorinated biphenyls in soil samples using an experimental design approach. Talanta, 50, 345-357. http://dx.doi.org/10.1016/S0039-9140(99)00028-4 